\title{
Ethnography Video of Qiang Traditional Music
}

\author{
Xiuming Li1,2 \\ ${ }^{1}$ School of Music, Shaanxi Normal University, Xi'an, Shaanxi, China \\ ${ }^{2}$ Teacher Education College, Sichuan University of Arts and Science, Dazhou, Sichuan, China \\ Email: 58958364@qq.com
}

How to cite this paper: Li, X.M. (2021) Ethnography Video of Qiang Traditional Music. Open Access Library Journal, 8: e7141.

https://doi.org/10.4236/oalib.1107141

Received: January 10, 2021

Accepted: February 6, 2021

Published: February 9, 2021

Copyright $\odot 2021$ by author(s) and Open Access Library Inc.

This work is licensed under the Creative Commons Attribution International License (CC BY 4.0).

http://creativecommons.org/licenses/by/4.0/

\begin{abstract}
This article briefly introduces the concept of music ethnography video and the 1st China Music Ethnographic Film Exhibition in Shanghai in 2019 and selects eight Qiang traditional music ethnography video works for evaluation, which are The Call of Erma: Folk Songs Chapter, Collect Folk Songs in Qiang mountain (with 3 DVDs), The Call of Erma: Qiang Flute Chapter, Qiang flute: cloud fly phoenix dance Leaving Flute Sound, The Call of Erma: Shibi Chapter, Silent and Lost Shibi, The Sky of Divine Nature, Ode to Sa Lang. These works are vivid chapters in the history of the Qiang traditional music ethnography video. It is of great historical and practical significance to better understand the Qiang traditional music culture and to produce more classic video of Qiang traditional music.
\end{abstract}

\section{Subject Areas}

Music, Ethnography

\section{Keywords}

Music, Video, Qiang, Tradition, Ethnography

\section{Introduction}

It is said that Huaxia, the predecessor of Han nationality, is a branch of Qiang nationality. Other branches of the Qiang nationality gradually developed into ethnic minorities with unique cultural temperament in Southwest China. In other words, one of the ethnic origins of many ethnic minorities in Western China can be traced back to the Qiang nationality. The Qiang people living in the upper reaches of Minjiang River in Northwest Sichuan have preserved a relatively intact traditional culture. This area is semi alpine and alpine, with short summer and cold winter. The Qiang nationality has its own language, which belongs to the Qiang branch of Tibeto Burman language family in Sino Tibetan language family, but no written record has been found so far. Qiang people call 
themselves Erma people. Their traditional music includes folk songs, Salang songs and dances, Shibi music, Shibi opera, Qiang flute, string of mouth and percussion instrument, such as sheepskin drum, etc. These traditional music cultures have been handed down for thousands of years and have been handed down from generation to generation.

Music ethnography video refers to the continuous, dynamic, and audible recording of the entire process of human music activities and related scenes through photographic technology. As a kind of knowledge of "Zhi", it includes objective recording and in-depth interpretation of musical cultural events. Music ethnography video is not only a method of music research, but also a material medium for the presentation of music culture. It is particularly important for the video recording of those ancient music cultures that are on the verge of extinction and loss. The academic world's expression of the meaning and important significance of music ethnography video history is: "Music ethnography video history is a modern academic method for the preservation, expression and research of music behavior and process. Using music ethnography video history methods can more closely relate to the cultural context of music production. In order to understand music more deeply, it is an important link in the development of musicology and art and an important path for the inheritance and spread of music culture" [1]. The audible and visual "writing" of music ethnography video is a useful supplement to the static recording of music culture with words, symbols, maps, recordings, photos, pictures, etc., and it is also the application of modern high-tech technology in the music discipline. It preserves the historical video of human music, injects new research paradigm into music discipline, and promotes the further development of music ethnography video discipline.

\section{Music Ethnography Video and the 1st China Music Ethnographic Film Exhibition}

Looking back at the development of audio and video technology, every invention and creation is the crystallization of human wisdom. In 1839, Frenchman Daguerre invented photography technology, in 1857 Frenchman Scott invented the sonic vibrometer (original recorder), and American Edison invented the phonograph in 1877. The subsequent masterpieces are even more iconic in the history of video. For example, the short films Train in the Station and Watering the Gardener filmed by the French Lumière brothers in 1895 marked the birth of silent films, and the American film in 1927 The King of Jazz marked the birth of sound films. In 1935, the American film Vivacious World marked the birth of the first color film. In 1936, the British Broadcasting Corporation (BBC) broadcasted a grand singing and dancing show at Alexandria Palace outside London. It marked the official start of the world's first television station. Chinese video also keeps up with the international pace. Early representative works include: China's first sound film Sing-song Girl Red Peony was born in China in 1931, 
and China's first color feature film Life, Death and Hatred was born in 1948. Since the 1990s, photography technology and computer digital technology have continuously improved, and the quality of video works has also been continuously improved. Its clarity, smoothness, and video quality have brought more visual beauty to people.

The advancement of science and technology promoted the rapid development of music art. Early ethnomusicologists used Wax Cylinder to record the earliest human audio materials during fieldwork. For example, in 1900, Stumpf, a representative of the Berlin School of Germany, and his disciples Hornbostel and Abraham jointly established the Berlin Audio Archive to record folk music from all over the world. In 1909, the Finnish linguist G. J. Ramstedt recorded a Mongolian historical recording (No. 1289-1337) in Ulaanbaatar, Mongolia, collected by the Austrian national audio-visual archives. The recording includes 32 folk songs, 4 lamas chanting sutras and the pronunciation of some Mongolian words. The recording includes 32 folk songs, 4 Lama chants and the pronunciation of some Mongolian words [2]. In 1950, Yang Yinliu and Cao Anhe went to Wuxi to record live music for Ah Bing. They recorded 6 works: Erhu music The Moon Over a Fountain, Listening to The Pines, Cold Spring Breeze Music, and the Pipa music Big Wave Washing the Sand, Dragon Boat, Zhao Jun Out of the Fortress. In 1993, the Chinese Traditional Ritual Music Research Project hosted by Cao Benye was established in the Music Department of The Chinese University of Hong Kong. The research project is ambitious and long-term. 1999-2001 took Southwest China and Northwest China as the research area, and 2003-2005 East China and South China as the research area. Each volume of the research achievement Research on Chinese traditional folk ritual music (northwest volume, southwest volume, East China volume and South China volume) is attached with VCD or DVD of field investigation. This is an earlier academic work equipped with case study video data among ethnomusicology works in mainland China. These historical collections of audio and video materials provide valuable video and historical materials for future generations to study human music culture. Throughout the music research of the 20th century and the beginning of the 21st century, although scholars are aware of the importance of sound and video data collection, collation and preservation, they also use them in practical research, but due to various technical and economic constraints, video technology is not used by most researchers. With the continuous improvement of video technology, the difficulty of using equipment has decreased, and more music researchers who have not mastered video professional technology are trying to use new technical routes to conduct research.

The International Conference on Film and Television Anthropology and the Ethnography Film Festival have also promoted the development of music ethnography video. In recent years, music ethnography films have been displayed in major music academic conferences at home and abroad, such as the international society of traditional music (ICTM), the European Chinese Music Research Fund/chime, and the annual meeting of the Chinese traditional music society. 
The 1st China Music Ethnographic Film Exhibition is an independent form of music ethnography video.

From August 26 to August 30, 2019, the 1st China Music Ethnographic Film Exhibition hosted by the Shanghai Conservatory of Music was held in the small theater of the Shanghai Grand Theater. This is the first time that a music ethnography video exhibition has been held in China. The organizing committee of this exhibition received a total of 62 works, including 53 in mainland China, 7 in Hong Kong, Macao and Taiwan, and 2 abroad. The film covers the music and cultural life of overseas Chinese and dozens of ethnic groups, including Han, Zhuang, Dong, Yao, Uygur, Yi, Tibetan, Miao, Lisu, Dai, Qiang, Jingpo, Naxi, $\mathrm{Wa}$ and $\mathrm{Nu}$ [3]. After the jury's viewing and selection, 43 works were promoted for re-evaluation, of which 30 nominated films were screened for lectures, and finally 20 films were nominated for final evaluation. In this event, 8 music ethnography video works were also invited to be screened, including Anthony Seeger's Why Suya Sings (50') and Hu Taili/Lu Yuxiu's Sound of Love and Sorrow (82'), Lu Shi $\mathrm{Ze}\left(15^{\prime}\right)$ by Liu Guiteng, An Other Country Is Hometown: Across the Ethnic Groups of Indonesian Chinese Culture and Artists (63') by Cai Zongde and Chen Jundian, Through Arirang's Road: Music of Koreans in Japan (76') by Terada Yoshitaka and Gao Zhengzi, Li Manshan: Portrait of an ancestral folk yin and yang $\left(85^{\prime}\right)$ by Li Manshan and Zhong Sidi, and Home Coming-The Ethnography of Dong (Kam) People's New Year by Cheng Qiaoqiao (40'), Patrick McGuire/Shen Najian's Big Nose and Body Music (45'), etc. At 19:30 on the evening of November 4, 2019, the Shanghai Grand Theater Buick Central Theater held the 1st China Music Ethnographic Film Exhibition final evaluation and award ceremony. The ceremony announced the gold and silver awards for music ethnography video and the best film awards Walking Ear, the winning works are:

Gold Award: Wu Shool Qin Say/Zhang Yang;

Silver Award: Music StudentsSound Year/Zhuang Min Ci;

Special Contribution Award: The Spring and Autumn of Study Center/Liu Xiaojin;

Best Director Award: Ke Zhi Juvenile-Ji Ze Er Qu/Lili Daha;

Best Photography Award: Bao Miao Festival/Zhang Fengying, Ning Yuanguai;

Best Field Record Award: Pray for Peace-Tai Ping Qing Jiao Ceremony at the Eighth Communities of Taohedutang, Haifeng, Guangdong/Hailufeng Investigation Team of the Chinese Music Ecology Team of Shanghai Conservatory of Music/Gong Daoyuan;

Best Record of Intangible Cultural Heritage Conservation: Qia Le Man, Ang Lai Man-“God Blow" Tohuti.Zaiding/Heli·Abdul Kader;

Outstanding Academic Idea Award: The Craftsman of God/Liu Xinru;

Outstanding Biography Award: Xiao Sound in Shanghai-The Musical Life of Mr. Dai Shuhong/Li Hailun;

Outstanding Newcomer Award: Ku Si La Pu/Xie Wanzhang;

Outstanding Exploration Award: Wa's "play tune"/Zeng Gochang [4]. 
From the 1st China Music Ethnographic Film Exhibition, the first Dream Voyage music ethnography video selection activity of the Guangxi University of Arts Conservatory of Music in 2019, and the development of the first graduate student recruitment of the Shanghai Conservatory of music ethnography video in September 2020, it marks a new step in the shooting, discipline construction and talent training of Chinese music ethnography video. The achievements are inseparable from the progress of science and technology, the joint efforts of several generations of music scholars, and the film and television professional directors, directors, and directors, participation of the producer. Today we have achieved results, we still need to realize that the current domestic music ethnography video history is still in its infancy. The construction and positioning of music ethnography video subject, the construction of teachers and teaching materials, the establishment of music ethnography video subject in relevant domestic universities and the training of talents, Teaching and research of music ethnography video, the responsibilities and missions of the director or investigator or speaker of music ethnography video, the way of expressing music ethnography video and academic standards, music ethnography video technology and post-production, the selection of music ethnography video topics and the quality of works, music ethnography video recording and cultural interpretation music A series of issues such as video recording and cultural interpretation are need of discussion. We believe that under the influence of philosophy, anthropology, film and television and other disciplines and the leadership of the "leader" of music ethnography video at the Shanghai Conservatory of Music, Chinese music ethnography video will usher in the spring of its disciplinary development.

\section{The Historical Stage of the Video Development of Qiang Traditional Music Ethnography}

\subsection{Before 1978: Photos Related to Qiang Traditional Music}

In the first half of the 20th century, scholars or missionaries from Britain, the United States, France and Japan came to the Qiang area. They used cameras to record the earliest images of the Qiang people. These photos mainly record the social and cultural life of the Qiang people. From the middle of the 20th century to 1978 , due to the backward equipment and technology, the traditional music ethnography video of Qiang people were almost blank in this period, and the image data were mainly photos.

\subsection{8-1998: Records, Tapes and Videos of Qiang Music}

At this stage, the Qiang culture documentary takes the Qiang traditional music as an embellishment and presents it in the form of background music. With the introduction of shooting equipment, shooting technology has also been applied to the production of traditional Qiang music. The formats of works include vinyl records, MT/disc audio tapes and MT/video tapes. This stage is the initial development stage of Qiang traditional music ethnography video, with only a few 
works. The production years are: three works in 1978, one in 1979, one in 1980 and one in 1991 [5]. This is the earliest audio-visual product of Qiang traditional music.

\subsection{8-2008: Qiang Traditional Music Style}

From 1998 to 2008, the shooting technology of Qiang traditional music image works has made some progress compared with the previous stage. Music short film (MV) is popular in domestic music circles, and Qiang traditional music is well known by the public in the form of folk film. The format of works in this period mainly includes CD/VCD, CD/CD, CD/DVD, one in 2004, one in 2005 and one in 2008. On May 12, 2008, an 8.0 magnitude earthquake occurred in Wenchuan, Sichuan Province. There were heavy casualties in the earthquakestricken area. The economy, culture, transportation, medical treatment, education and other undertakings were severely damaged. The Qiang compatriots were in the hardest hit areas. A few days before the earthquake, Wang Jingquan's traditional Qiang music was made into a music record Millennium Ancient Songs (DVD). Through shooting the real scene, the Qiang compatriots performed nine Qiang Tibetan multi voice folk songs, presenting the cultural customs of the Qiang inhabited areas before the earthquake. This work is a representative work of this period [6]. After 1998, with the development of network technology, the storage and presentation of Qiang traditional music video in the form of network has been initially developed. The storage location of network music includes personal network space and public network platform. There are more than 100 audio-visual materials on the Internet. These works are very precious historical materials of Qiang traditional music [7].

\subsection{8-2020: Traditional Music TV Programs and Ethnography Micro Films of Qiang Nationality}

After the disaster, cultural reconstruction has become a top priority. National and local TV stations have produced relevant programs to record the traditional music culture of the Qiang nationality, which are preserved and commemorated as precious audio-visual materials. From May 11th to 16th, 2010, CCTV15 music channel Folk Song China column broadcasted six consecutive issues of Qiang mountain sentiments rhythm (each issue lasts nearly half an hour); March 16, 2011, CCTV15 music channel Feng Hua Chinese Music column broadcast Bi Man Group Qiang Multi-voice Win; from May 9th to 14th, 2011, the Folk Songs China column of CCTV15 music channel once again broadcasted six consecutive issues of Impression of Qiang Mountain (each program lasts nearly half an hour). These programs show the colorful folk songs and folk customs of the Qiang people. Maoxian TV station in Sichuan province takes the regional advantage of Qiang culture core area, carries forward and shows the long history of Qiang as its own responsibility, and shoulders the mission of cultural Self-Building.

In May 2011, a series of Qiang culture documentaries were broadcast in the Minjiang column of Qiang channel. In this column, the theme of The Call of 
Erma presents such important music chapters as The Call of Erma: Folk Songs Chapter, The Call of Erma: folk songs Chapter, The Call of Erma: Qiang Flute Chapter, The Call of Erma: Shibi Chapter (as a cultural documentary video, the theme also includes The Call of Erma: Qiang embroidery in the same period). The three Qiang traditional music documentaries of the special topic The Call of Erma all belong to the intangible cultural heritage of the Qiang. The traditional music culture of the Qiang is spread through video, which shortens the distance between the audience and the traditional music of the Qiang. This is an early representative work in the history of Qiang traditional music by using the technique of film and television anthropology to record the video of Qiang traditional music.

On April 25, 2012, Sichuan Conservatory of Music held a Qiang song special concert Hua Er Na Ji (the preview lasted about 2 hours). The creative team of the academy refined and processed on the basis of the preview. On June 30, 2012, it was officially performed in the form of Large-scale original music poetry, which interprets Qiang traditional folk songs and Qiang style songs.

In 2019, He Wangjin and Zhao Fushou performed The Love of Qiang Mountain in the China Instrumental Music TV Competition of China Central Radio and Television, which was adapted from the folk song of the Qiang nationality into a Qiang flute song, it shows the Qiang people's nostalgia for the mountains and their pursuit of a harmonious life state of nature, the production process of Qiang flute is also shown in the performance. Videos related to the traditional music of the Qiang ethnic group include Collect Folk Songs in Qiang mountain, Silent and Lost Shibi, The Sky of Divine Nature, Ode to Sa Lang, Qiang Flute: cloudflyphoenix dance Leaving Flute Sound, etc.

\section{Discussion on Ethnographic Videos of Qiang Traditional Music}

\subsection{Cultural Reconstruction Thank for Benefactor, Colorful Folk Songs to Nourish the Soul-The Call of Erma: Folk Songs, Collect Folk Songs in Qiang Mountain}

The Call of Erma: Folk Songs (29'09") through interviews with characters, introduction to music activities and behind-the-scenes commentary, let the public know the classification, style characteristics, and development trends of Qiang folk songs. The interviewers in the film include Yin Zhong, the director of the musical Qiang Soul, Chen Guangrong, the original actor of the crew, Chen Qingchao, the daughter of Chen Guangrong who went to university, Fu Rundong, who founded the Qiang Music Association at the university in 2005, and Aba Tibetan and Qiang Autonomous Prefecture Yang Xiaofang and Jiang Mingjun from the secondary vocational technical school, Li Jiaji, researcher of Maoxian Cultural Center, writer Lei Zi, and Wei Qing, curator of Maoxian Cultural Center, etc.; the film also introduces two Qiang brothers Bi Man (Ze Wang Ren Qing and Ge Lo Za Xi) from Songpan County, Aba Prefecture in the origi- 
nal singing competition of CCTV Qingge competition in July 2006. Their Qiang drinking song Can't Sing won the bronze prize in the competition; Maoxian Cultural Center organizes Qiang folk songs and is committed to the protection and inheritance of Qiang folk songs; The song and dance drama Qiang Soul created by Maoxian Song and Dance Troupe has toured in Chengdu, Beijing, Shanghai, Taiwan and other places, demonstrating the confidence of the Qiang ethnic group to rebuild their spiritual homes. They used song and dance culture to thank all sectors of society for their assistance in the earthquake. The film presents the efforts and consciousness of the Qiang people in protecting, inheriting, and promoting traditional national culture from different aspects.

Collect Folk Songs in Qiang mountain (3 DVDs about 7 hours long) was edited by Wan Guangzhi. The book integrates sound, video, score, and text. The three DVDs at the end of the book are actual records of live performances by singers corresponding to the 277 Qiang folk songs in the book. In addition to singing, there are singing and dancing, instrumental solo and accompaniment. In the preface, the editor said that the recorded video "exclude any hint or preview", and strive to "have a full sense of presence and reality." Among the 277 Qiang folk songs, except for the 6 folk songs in Appendix II that were sung by Tibetan compatriots, the rest were sung by Qiang compatriots. The video presents the original and authentic Qiang folk songs. From July 2004, Wan Guangzhi led the team to go to the Qiang District to conduct field recordings to May 2011 at the Great Hall of the People in Beijing to hold the new book Collect Folk Songs in Qiang mountain conference. In the seven years, the recording team went to Qiang District to film several times, has brought us precious music ethnography video. In 2011, on the occasion of the third anniversary of the Wenchuan earthquake, Collect Folk Songs in Qiang mountain was published before the author's Sichuan Folk Songs Collection (2017), aiming to in memory of the dead and comfort the living. The whole society is concerned about the cultural survival status of the Qiang ethnic group, as well as post-disaster cultural and spiritual reconstruction [8]. At the time of publication, Collect Folk Songs in Qiang mountain received 200,000 Yuan publishing support from China Publishing Group Corporation. In December 2013, it won the 3rd China Publishing Government Award. Since its publication, the work has received unanimous praise and is called an ethnography of unique academic value and practical significance [9]. It is of great significance to music performance, creation, research, and even the promotion of Chinese national music culture, and the inheritance of the Chinese national spirit. Here, I call it the historical value of Qiang traditional music ethnography video. This work and The Collection of Sichuan Folk Songs is a model of epoch-making significance in the history of Chinese music. It has been fully affirmed by the academic circles from the angles of musicology, art history, literary history, national history, cultural history, etc., and is called "Living Literature". As the author said: "Folk songs are the most vital part of the 'living literature', and a vivid testimony to the history of national survival and 
culture" [10]. Folk songs not only testify to history, but also nourish the soul. Folk songs are an important part of people's lives. Living in a sea of poetic and picturesque folk songs is a tradition that has remained unchanged for thousands of years. In the era of cultural diversity, folk songs have their own unique charm of blooming brilliance.

\subsection{The Sound of Flute Spreads to Qiang Village, Ancient Rhyme, Free Spirit, Open Heart-The Call of Erma Qiang Flute, Qiang Flute Cloudflyphoenix Dance Leaving Flute Sound}

The Call of Erma: Qiang Flute (27'31") tells the story of Gong school, the founder of the Qiang flute Gong school, Chen Haiyuan, the second-generation successor, He Kezhi, the founder of He school, and He Wangquan, the second-generation successor. The story about the protection and inheritance of Qiang flute by $\mathrm{He}$ Meiyan, a three-generation successor. In the film, He Wangquan said: "My old partner Chen Haiyuan, we are the inheritors of the Qiang flute, because the inheritors have obligations, including its reform. Qiang flute used to be more solo, and it was difficult to combine with other instruments. It's about whether or not it is possible to play two Qiang flutes, or even three Qiang flutes, four Qiang flutes, and more Qiang flutes together. Five or six years ago (2005), we slowly ran into each other during the performance. Some repertoires can be played in duets, and those that can be played in multiples are tried." The Qiang flute inheritor Chen Haiyuan and He Wangquan tried to create the Qiang flute duet Qiang Mountain Love for the first time with a beautiful melody and pleasant sound, bringing the listener into a distant artistic conception and a primitive charm. The work has been performed on stage many times. Chen Haiyuan said: "In recent years, the introduction of Qiang Di on the stage has been promoted both at home and abroad, so we are now including the music on our stage and some modern shortcuts. Qiang flute is a traditional instrument of the Qiang and an ornamental effect in traditional music. Because it is made of arrow bamboo on the mountain, its sound is very unique and beautiful. The background music of Qiang flute is very good in our large-scale stage performance and the long history of our nation." Chen Jinlong, President of Maoxian Erma culture (Qiang flute Shibi) association, said: "Nowadays, many young people are unwilling to learn because it is too difficult. Therefore, we should start from small children and do a good job so as to arouse everyone's interest. As Erma people, they have the obligation and ability to pass on the original ecological things of Qiang flute because it is the original ecological things. If it is not passed on, this basically it will be lost, so we grabbed the baby and passed on the original things of the Qiang." In addition, the film also presents the craftsmanship of Qiang flute: The first step is to collect the original material-arrow bamboo or oil bamboo, which generally grows more than 3000 meters by the sea, and then they are collected and placed in a farmhouse for smoking. Smoke generally takes half a year. The second step is rough machining. There is a choice for rough machining. The 
diameter of double holes should be consistent. After collection, they should be soaked in oil for up to half a year. In the third step, fine processing is started, processed into a double tube, and then drilled after playing and polishing, but the key production of the Qiang flute is mainly in the reed. The Qiang flute is composed of double reeds, and the double reeds must be polished and processed for a long time to make a sound. It's done. Through the video display, we can intuitively understand the requirements of the selection of materials for the Qiang flute and the detailed production process, and also let us feel the new hope for the future development of the Qiang flute. On the CCTV music channel Folk Songs China (2011), a quartet composed of four Qiang flutes and eight chords Qiang mountain Love was broadcast. The key to the success of this work lies not only in the attempts and efforts made by the Qiang nationality to innovate and develop their own national music culture, but also in the uniqueness and aesthetics of the Qiang flute and mouth strings.

Qiang flute: cloudfly phoenix dance Leaving Flute Sound (13') is one of the series of research on the Qiang folklore of college students. The authors Yang Hangxia, Zhang Lifei, Yang Haoqin, Zhou Zhaoxu, Chen Xichuan, Pang Jiaqi, uploaded online in 2017. The work first presents the self-reporting of Chen Haiyuan (Qiang's name is Kolova), the first batch of provincial-level inheritor of Qiang flute playing and making skills in Sichuan Province. According to Chen Haiyuan, he has been learning Qiang flute since the age of 12. He said: "(Qiang flute) it's sad, so this nation has gone through ups and downs. Therefore, the main tune of Qiang flute is sad and a kind of sad tune.” The film's commentary mainly tells the ancient history of the Qiang and the making skills of the Qiang flute. The commentary is interspersed with Chen Haiyuan's narration, Qiang flute teaching and Qiang flute production process, the film tells the production steps of Qiang flute: selecting bamboo, arranging bamboo, passing bamboo, cutting bamboo, sticking bamboo, winding bamboo, fixing hole, drilling, making reed, making Decorate and make bamboo sets. The film finally shows that Qiang Di enters the campus in the form of a course. There is a Qiang flute interest class in Feng Yi Primary School in Maoxian County, and the inheritor Yang Baling is responsible for teaching. From the film, we can feel the profound feelings of generations of Qiang flute people for Qiang flute. "The sound of Qiangdi brings people a kind of happiness." This remark of the old man Gong Dairen shows the aesthetic entertainment value of Qiangao County. In the film, the verbal narrations of the old Shibi elders Yang Zhide and Xiao flute, this is also one of the values of high art.

\subsection{Respect the Heaven, the Earth and the Ancestors, Looking for Successors of Scripture, Drum, Dance, Drama-The Call of Erma: Shibi, Silent and Lost Shibi, the Sky of Divine Nature}

The Call of Erma: Shibi Chapter (16'32") tells the source, current situation and future prospects of the legendary Qiang Shibi. Title Record: July 17, 2010, Napu 
Village, Yonghe Township, Mao County. In the film, the verbal narrations of the old Shibi elders Yang Zhide and Xiao Yongqing, the descendants of Shibi Bai Futong and Liu Zhengao, the researcher Li Jiaji of the Maoxian Cultural Center, and Luo Zhongbo, the vice president of the Erma Culture (Qiang flute Shibi) Association, present the profound connotation of Shibi culture. Shibi regards "saving people" as his duty and mission. From a spiritual level, "saving people" is a kind of belief and sustenance of people, giving people spiritual power, but the current status of Shibi inheritance makes the old generation worried. At the end of the film, Luo Zhongbo said: "In order to promote, excavate, develop, and inherit traditional culture and traditional history, (to) we Qiang people, under the leadership of the party, we should be like 56 flowers in our 56 ethnic groups, so that the flower of Qiang people will be more colorful and beautiful."

Silent and Lost Shibi (48'12") is the graduation project of MFA master's degree in Art (film) of Southwest Jiaotong University, which was completed by Tian Dong, Zhao Xi and Wei Xike in 2012 under the guidance of their tutors. This film focuses on the life situation of Yang Guisheng, an Ancient Qiang Shibi cultural promoter based in Xige Group, Jiaopo Village, Longxi Township, Wenchuan County, Aba Prefecture, Sichuan Province after he was relocated in another place due to the 2008 Wenchuan Earthquake (relocated in September 2009) and relocated to Muti Village, Nanbao Township, Qionglai City, Sichuan Province. The film presents Yang Guisheng's concerns about the inheritance of Shibi culture and the mission and responsibility as the inheritor of Shibi under the reality of the commercialization of Shibi culture. Facing the changes of Shibi culture, the work highlights the lost situation of Shibi. In the author's master's thesis, the author introduced the background and meaning of the documentary creation, namely: Tian Dong's the Importance of Director, Camera and Editing in Documentary Films-Taking the Shooting of Silent and Lost Shibi as an Example, Zhao Qian's Documentary Silent and Lost Shibi Theme Design Analysis, Wei Xike's Documentary Video Collection and Writing from the Perspective of Film and Television Anthropology-Taking the Documentary Silent and Lost Shibi as an Example.

The Sky of Divine Nature (45'18") was directed by Qiang director Yi Xi, and was jointly produced by China Intangible Cultural Heritage Research Institute, Wenchuan County Culture, Sports, Radio, Film and Television Press and Publication Bureau, and Nayi (Beijing) International Culture Media Co., Ltd. Production time 2016. This film is composed of six Qiang people, including Yang Shuishui (Yang Guisheng's brother), the inheritor of ancient Qiang Shibi culture, Zhu Jinlong, the inheritor of sheepskin drum production and skills of the national intangible cultural heritage, Yang Guisheng, the inheritor of ancient Qiang Shibi culture, Zhao banglan, the inheritor of Qiang Shibi culture, Zhao Bangan, the inheritor of Qiang Shibi culture, and Wang Zhisheng, the national intangible cultural heritage of Qiang, are the main line. The unique Qiang culture and the beautiful Minjiang River landscape are presented through the oral narration of the inheritors and the activities of Qiang people's sacrifice, stepping 
on the Hua Tou, sheepskin dance, and needling. The work won the Golden Feather Wing Best Documentary Award at the Fifth China International Micro Film Festival in 2016. In the same year, it was nominated for the 13th World National Film Festival in Los Angeles, USA. In 2019, it was nominated for the 1st China Music Ethnographic Film Exhibition and was re-evaluated and selected as a lecture-style screening.

\subsection{Be Good at Singing and Dancing to Teach Women, Sing and Dance Ode to the Goddess-Ode to Sa Lang}

Ode to Sa Lang $\left(45^{\prime}\right)$ is a work of Qiang traditional music ethnography video directed by Liu Guangyu. Sa Lang means to sing and dance. This traditional song and dance custom has a long history. Its origin can be found in many legends, such as the classic of Shibi of Qiang nationality, taking kindling and sister Salang. The most moving one is the legend of sister Sa Lang, which is full of mythological color. There are many versions of the legend about sister Sa Lang. Generally speaking, sister Sa Lang is good at singing and dancing and Qiang embroidery. Qiang women have asked her for advice. People built a stone tower (goddess Liang Zi) for her to commemorate her. This commemorative song and dance activity gradually evolved into a large-scale comprehensive folk festival with certain ritual procedures-Wa Er E Zu Festival. Every year from the third to the fifth day of the fifth lunar calendar, a three-day celebration is held. The festive atmosphere is warm, women Immersed in the ocean of joy, therefore, the Wa Er E Zu Festival is also called the Qiang Women's Day, and Sa Lang has also become synonymous with singing and dancing. According to different functions and social meanings, Sa Lang can be divided into "Sorrowful Salang" and "Happy Celebration Sa Lang". The folk beliefs of ancient Qiang goddess worship can be interpreted from the form presented in the music ethnography video Ode to Sa Lang, and some scholars have interpreted it as the cultural origin of the ancient Qiang nationality's matriarchal clan. Since 2015, Southwest Jiaotong University has undertaken a number of sub-projects of the National Social Science Fund's special commissioned project Chinese Festival Video Records, and Qiang Wa Er E Zu Festival is one of the sub-projects. Ode to Sa Lang was shortlisted for the Society Award of the Film and Television Anthropology Branch of the Chinese Society of Ethnology in 2017. It was also evaluated in "The second forum on the relationship between cross-border ethnic groups and neighboring countries \& the annual meeting of film and television anthropology branch of Chinese ethnological society in 2017"; the 1st China Music Ethnographic Film Exhibition in 2019, the work was shortlisted as one of the 20 films finally nominated.

\section{Conclusions}

The production teams of the eight Qiang traditional music ethnography video works analyzed in the previous article come from TV stations, universities and 
media companies. They have both professional productions in film and television and student work. Some of the works have high social evaluation. The producers are TV producers, directors, college teachers, college students, etc. The types of works marked include documentary micro-films, documentaries and video. Although each type has a very clear difference according to different needs or uses, the similarity between each other is extremely high. For example, they all adopt objective and true documentary techniques, anthropological theories and methods, and hermeneutic theories. They do not take box office revenue as the highest goal. They also focus on the same theme-Qiang traditional music or culture related to Qiang traditional music. Therefore, this article tentatively includes these three types of works in the Qiang traditional music ethnography video.

From the perspective of the length of time, the three works of Silent and Lost Shibi, The Sky of Divine Nature and Ode to Sa Lang are all 45 minutes in length, and the other works last from ten minutes to several hours. In the 1st China $\mathrm{Mu}$ sic Ethnographic Film Exhibition, we saw that the music ethnography video works lasted from 10 minutes to 90 minutes, and the producers included investigators, directors or speakers. This also shows that music ethnography video paves the way for the construction of the discipline itself with an open and integrated attitude. From the perspective of entry point, The Call of Erma: Folk Songs tell that the Qiang nationality consciously assumes the historical responsibility of inheriting the national song and dance culture. The Call of Erma: Qiang Flute, Qiang Flute: Yun Fei Feng Yi Liu Di Yin cloud fly phoenix dance Leaving Flute Sound is based on the production of Qiang flute, inheritance and innovation of Qiang flute inheritors. The Call of Erma: Shibi Chapter, Silent and Lost Shibi, The Sky of Divine Nature the current situation of the inheritors of Shibi and the changes of Shibi culture. Ode to Sa Lang presents the grand traditional culture of the Qiang from a female perspective. From the perspective of expression, there are some local people who narrate or sing, and some demographic narrative and outsider communication (or post-production commentary and subtitles) are jointly expressed. Although the presentation methods are different, they have the same thing in that they give the narrative power to the insiders, that is, the main characters in the video.

The interpretation of "Zhi" in "Shuo Wen Jie Zi" is "Idea. From the heart, the voice" [11]. From the perspective of "Zhi", the music ethnography video describes and interprets the cultural meaning of music in the form of video. The core is the "voices" of the "people" in music events, and the understanding of the "voices" of cultural holders is the ideological premise. "The heart moves, and things make it happen." This may be the soul of the music ethnography video. The above-mentioned 1st China Music Ethnographic Film Exhibition won the special contribution award Chuan Xi Guan Chun Qiu. This is a masterpiece with a deep soul. Producer Liu Xiaojin started with the Yunnan National Culture Museum opened by Tian Feng in November 1993. It has been shooting for seven 
years and four years of post-production. Whether it is Tian Feng who relies on personal and folk power to find, rescue, protect, and inherit the lost national art in the video, or the long-term follow-up of the producer, the hard work they have put in to inherit the national music is touching. It was disbanded in June 2000 after seven years of opening, but the deeds of Tian Feng and Study Center awakened the consciousness of the Chinese people about national culture. The Study Center has cultivated a group of folk artists who are conscious of the protection and inheritance of national traditional culture. With the kind invitation of 22 of them, Liu Xiaojin formally established Yuan Sheng Fang in 2004, opening the road of village inheritance, also found the spiritual homeland for folk artists. The common sense of mission supports people who love national culture to continue the cultural undertakings Tian Feng expects. Yuan Sheng Fang is also the continuation of Tian Feng's spiritual power. Liu Xiaojin believes: “The folk art of ethnic minorities, their music, singing and dancing is really too nice and charming. The current urban culture or everything is irreplaceable, and their sound elements cannot be replaced. Duplicate and irreplaceable, it is too unique and unique", "even if there is money attached to some aspects, we must support national culture" [12]. Whether it is Tian Feng, the protector of national culture, or Liu Xiaojin, who is a choreographer and social worker, they all support and adhere to national art through their personal strength.

Variants related to "Qiang" in the oracle bone inscriptions, archaeological discoveries and ancient documents prove that the Qiang is the oldest ethnic group in the Chinese nation and the source of many ethnic groups today, with a long history and unique cultural knowledge system. Regarding the traditional music ethnography video of the Qiang nationality discussed in this article, how does the traditional music ethnography video of the Qiang nationality describe its splendid culture, how to highlight the characteristics of the "Zhi", and how to realize the aesthetic construction of the traditional music of the Qiang nationality in the video? Does the Qiang traditional music ethnography video work provide an in-depth interpretation of the cultural connotation of the Qiang traditional music? Does it reflect the philosophical thinking of the nation, and does it leave room for viewers to think? ...This series of questions is worthy of our in-depth consideration. A valuable music ethnography video work depends on the depth of the video expression. The shooting and production of Qiang traditional music video should reflect the philosophy of life contained in Qiang culture, rather than record the superficial cultural phenomenon, which is the ideological and cultural basis for promoting the development of Qiang traditional music video. The innovation of this paper is to sort out the historical stages of the development of Qiang traditional music ethnography video, analyze the cultural connotation of the existing Qiang traditional music ethnography video works, and bring the traditional music video of Qiang nationality into the horizon of Ethnography. Our contribution lies in providing a certain experience basis for the shooting of new video works. We are looking forward to the emer- 
gence of more classic Qiang traditional music ethnography video works.

\section{Acknowledgements}

The author would like to thank Sichuan University of Arts and Sciences for their support.

\section{Conflicts of Interest}

The author declares no conflicts of interest regarding the publication of this paper.

\section{Funding}

Sichuan University of Arts and Sciences 2017-2019, 2020-2022 school level education and teaching research and reform general project (subject number: 2017JY37; subject number: 2020JY108).

\section{Notes on Contributor}

Li Xiuming (1980-), female, Ph.D. candidate in the School of Music of Shaanxi Normal University; associate professor of the Teacher Education School of Sichuan University of Arts and Science. Mainly engaged in folk music culture research, she published the academic monograph The Study of Music Anthropology in Sichuan Zuo Ge Tang (Bashu Press, 2021).

\section{References}

[1] Xiao, M. (2019) The Construction and PROSPECT of Music Iconography \& on the Documentary and Expression of Music Ethnography Video. The 70 th Anniversary Celebration of Xi an Conservatory of Music and the "Spring and Summer Academic Month" Series of Activities of the Department of Musicology, Xi'an, 20-28 June 2019, 10.

[2] Xiao, M. (2015) Musical Anthropological Interpretation of Modern Historical Sound/Image. National Art Research, 6, 8-9.

[3] He, L.T. (2019) Shanghai Conservatory of Music, China Academy of Music Advanced Research Institute, Shanghai Conservatory of Music Asia-Europe Music Research Center: The Latest Report of "the 1st China Music Ethnographic Film Exhibition Collection". Ceremonial Music Center (Shanghai Conservatory of Music "Chinese Ritual Music Research Center" Public Account).

[4] He, L.T. (2019) Shanghai Conservatory of Music, China Academy of Music Advanced Research Institute, Shanghai Conservatory of Music Asia-Europe Music Research Center: Award Winning List of the 1st China Music Ethnographic Film Exhibition/Review of Award Ceremony. Ceremonial Music Center (Shanghai Conservatory of Music "Chinese Ritual Music Research Center" Public Account).

[5] Song, X.B. (2010) Index of Qiang Music Documents (1949-2009). Sichuan University Press, Chengdu, 154-155.

[6] Wang, J.Q. (2009) Millennium Ancient Songs. Sichuan Literature and Art Audio Visual Publishing House Chengdu.

[7] Song, X.B. (2010) Index of Qiang Music Documents (1949-2009). Sichuan University Press, Chengdu, 155-169. 
[8] Wan, G.Z. (2011) Collect Folk Songs in Qiang Mountain. Beijing, People's Music Publishing House.

[9] Tang, X.L. (2012) Rescuing the Legacy on the Bite of the Tongue-Collect Folk Songs in Qiang Mountain: An Ethnography with Unique Academic Value and Practical Significance. Forum on Chinese Culture, 2, 183.

[10] Wan, G.Z. (2018) Folk Songs: Living Documents from the Field. Journal of Literature and History, 5, 15.

[11] Xu, S. (2007) Shuo Wen Jie Zi. Shanghai Ancient Books Publishing House, Shanghai.

[12] CCTV Network Video, Half the Sky (2008) Chuan Xi Guan Chun Qiu, 232. http://tv.cntv.cn/video/C16687/ffd135355f6b459113b2828fa5d6b850.2014-04-11 